J. Amer. Soc. Hort. SCI. 120(1):152-157. 1996.

\title{
Lychee Pollination by the Honeybee
}

\author{
Raphael A. Stern ${ }^{1}$ and Shmuel Gazit ${ }^{2}$ \\ The Kennedy-Leigh Center for Horticultural Research, The Hebrew University of Jerusalem, Faculty of \\ Agriculture, Rehovot 76100, Israel
}

Additional index words: Apis mellijera, flower, Litchi chinensis, nectar, pollen

\begin{abstract}
Pollination of lychee (Litchi chinensis Sonn.) by the honeybee was studied in Israel's two commercial cultivars, 'Mauritius' and 'Floridian'. Pollination rate, which was determined in a mixed 'Mauritius' and 'Floridian' plot, followed a consistent pattern: it was low at the first male (M,) 'Mauritius' bloom and reached a high value only when the pseudohermaphroditic $\left(\mathrm{M}_{2}\right)$ 'Mauritius' bloom started. Pollen density on bees collected from 'Mauritius' inflorescences was very low during the $M$, bloom and increased to very high values during the $M_{2}$ bloom. These results indicate that the 'Mauritius' M, bloom does not play an important role as a source of pollen for pollination. Pronounced, significant, and consistent differences in nectar volume per flower and sugar concentration in the nectar were found between $M_{1}, M_{2}$, and female (F) 'Mauritius' flowers. Values were very high in $F$ flowers, medium in $M_{2}$ flowers, and low in $M$, flowers. Accordingly, the density of bees found on inflorescences was high during the $F$ bloom, intermediate during the $M_{2} b l o o m$, and low during the $M_{1}$ bloom. The positive correlation between bee density and sugar concentration in the nectar was highly significant for $M_{2}$ and $F$ 'Mauritius' flowers. The nectar contained three sugars: glucose (43\%), fructose (39\%), and sucrose (18\%). This ratio was the same in nectar from $M_{1}, M_{2}$, and $F$ 'Mauritius' flowers.
\end{abstract}

The lychee, which originated in China, was introduced to Israel in the 1930s. Only two cultivars have been planted commercially: 'Mauritius', introduced from South Africa, and 'Floridian', introduced from the U.S. The latter is probably a seedling of cv. Brewster (Degani et al., 1995b). Low productivity of the commercial lychee orchards in Israel prompted a study of its pollination.

Lychee flowering in Israel occurs in late spring and lasts for about a month. Three distinct flowering waves can usually be observed in every in florescence. Each wave consists of flowers of the same type: the first wave consists of male flowers $\left(M_{1}\right)$, the second of female flowers $(\mathrm{F})$, and the third of pseudohermaphroditic flowers, which function as males $\left(\mathrm{M}_{2}\right)$ (Costes, 1988; Joubert, 1986; Scholefield, 1982; Stern et al., 1993 b). There is a similar number of open flowers at each wave (Stern et al., 1993a). The transition between waves in the same inflorescence is distinct. The anthers in $\mathrm{M}$, and $\mathrm{M}_{2}$ flowers dehisce gradually throughout the day and night (McGregor, 1976; Menzel, 1984), with peak releases of pollen occurring in the morning. Female flowers remain receptive for 3 days from anthesis (Chaturvedi and Saxena, 1965).

Since lychee flowers are functionally unisexual, fruit set can occur only if pollen from male flowers $\left(\mathrm{M}_{1}\right.$ and $\left.\mathrm{M}_{2}\right)$ is transferred to the stigma of $\mathrm{F}$ flowers. Lychee flowers are entemophilic and pollination is usually performed by insects, one of which is the honeybee (Free, 1993; King et al., 1989; McGregor, 1976). A large number of insects, especially bees, visit lychee flowers, mainly during the morning hours (Free, 1993; Pivovaro, 1974). Adequate pollination is ensured by the fact that the $F$ flowering wave occurs between two pollen-releasing waves $\left(M_{1}\right.$ and $\left.M_{2}\right)$, and by the abundance of pollinating agents (Butcher, 1956, 1957; DeGrandiHoffman, 1987; Groff, 1943; McGregor, 1976; Pandey and Yadava, 1970), provided that weather conditions do not limit bee activity (Menzel, 1984).

Received for publication 21 Mar. 1995. Accepted for publication 7 June 1995 Contribution from the Faculty of Agriculture, Rehovot, Israel. We thank Hillary Voet for her valuable assistance in the statistical analysis. The cost of publishing this paper was defrayed in part by the payment of page charges. Under postal regulations, this paper therefore must be hereby marked advertisement solely to indicate this fact.

'Research horticulturist. MIGAL, Galilee Technological Center, P.O. Box 90000, Rosh-Pins 12100, Israel.

${ }^{2}$ Professor. Kennedy-Leigh Center for Horticultural Research, Faculty of Agriculture, P.O. Box 12, Rehovot 76100, Israel. To whom reprint requests should be addressed.
To date, there have been no reports on the relationship between bees and the different types of lychee flowers, or the efficiency of the bee as a pollinator for lychee (McConchie and Batten, 1989). The aim of this work was to study the pollination rate in lychee, and the attractiveness of the three flower types to bees.

\section{Materials and Methods}

Flowering phenology. During the blooming period, flowering was monitored every other day.

Pollination rate. Flowers were randomly sampled about 2 days after anthesis (Chaturvedi and Saxena, 1965). Pollination rate was determined by three methods.

a) Stereomicroscope (STM): Eisikowitch and Melamud's (1982) technique was adapted for lychee. Styles were severed in the orchard and immediately placed in a very viscous CMC solution (3 $\mathrm{g}$ of carboxymethylcellulose dissolved in a solution of 70 $\mathrm{ml}$ water $+20 \mathrm{ml}$ glycerin $+10 \mathrm{ml}$ ethanol + a few grains of aniline blue) on a mounting glass. The presence of pollen grains on the stigma was determined the same day by STM $(80 \times$ magnification).

b) Fluorescent microscope (FLU): Styles were fixed in an 2 ethanol $: 1$ acetic acid solution (Rabat, 1970). After several days, the styles were transferrd to $8 \mathrm{~N} \mathrm{NaOH}$ for about $48 \mathrm{~h}$, for softening and clarification, then rinsed thoroughly in water, and stained with aniline blue (Martin, 1959).

c) Scanning electron microscope (SEM): Styles were fixed in $75 \%$ ethanol and prepared for observation using Jennersten et al.'s (1988) technique. The stigma surface was scanned for pollen grains in a Jeol JSM 35C SEM (Japan).

Number of bees per inflorescence. In 1989 and 1990, at around 0700, 1000, and 1700 every other day, we counted the number of bees present on 'Mauritius' inflorescences at the $\mathrm{M}_{1}, \mathrm{~F}$, and $\mathrm{M}_{2}$ stages. At each flowering stage, 10 inflorescences (five trees $\times$ two inflorescences) were observed.

Pollen on bee's body. Bees present on all three types of 'Mauritius' inflorescences ( 10 bees from each type) were collected in carbon tetrachloride killing jars (Ish-Am and Eisikowitch, 1993; Kearns and Inouye, 1993) every other day, at around 0700,1000, and $1700 \mathrm{HR}$. The bees were coated with gold for $30 \mathrm{~min}$ and examined in a Jeol 35C SEM (Anderson et al., 1982; Kearns and Inouye, 1993). The amount of pollen on the bee's body was graded as follows: $0=$ no pollen; 1 
$=\mathbf{a}$ few pollen grains; $2=$ tens of pollen grains; $3=$ hundreds of pollen grains (Ish-Am and Eisikowitch, 1993).

Nectar. Nectar volume and the concentration of its sugars were determined every other day during peak bloom $(21,23,25$, and 27 Apr.) in all three types of 'Mauritius' flowers. Only fully opened flowers, about 1 day old, were sampled. Nectar was collected by suction with a micropipette from open flowers, which were available for bee visitation (standing crop), and thus reflected the state of the nectar at time of collection but not the rate of nectar production. Nectar was collected between 0600 (about half an hour before the start of bee activity) and $1000 \mathrm{HR}$. After $1000 \mathrm{HR}$ the amount of nectar was too low to collect. Its disappearance was apparently due to collection by the bees, and to evaporation. The concentration of total soluble solids (TSS) was determined with a hand-held Stanly and Bellingham refractometer calibrated against a standard sucrose solution (Corbet, 1979; Cruden et al., 1983). Ten flowers (replicates) were used for each determination. The concentration of sugars in the nectar was determined in 1989. For each replicate, $1000 \mu \mathrm{l}$ of nectar was collected from each flower type. The nectar was placed in 2-ml Eppendorf tubes and kept in a freezer $(-18 \mathrm{C})$ until sugar level determination by HPLC (Piccaglia and Galletti, 1988).

\section{Results}

Flowering phenology. Flowering of the two commercial lychee cultivars in Israel, 'Mauritius' and 'Floridian', was studied in mature orchards ( 2 in 1988, 4 in 1989, and 11 in 1990) located in all-lychee growing regions (Fivaz, 1994). We did not encounter deviations from the typical flowering succession in any of the 17 observations. In each cultivar, three flowering waves occurred. Fig. 1 presents the typical flowering phenology, as observed on three separate occasions. In each orchard there was a first wave of functional male flowers ( $\mathrm{Ml})$, a second wave of functional female flowers (F), and a third wave of functional male flowers (M,). Each wave lasted for 7 to 10 days. Partial overlapping occurred between the female and two male-type waves in both cultivars. Such overlapping was rare within the same inflorescence, but occurred between inflorescences on the same tree, and was especially noticeable between different trees.

There was a consistent difference in flowering time between the two cultivars (Fig. 1), with 'Mauritius' being the first to flower, and 'Floridian' following suit about a week (4-12 days) later. As a result, there was a solid overlap between the 'Mauritius' F bloom and the 'Floridian' $\mathrm{M}_{1}$ bloom, and between the 'Floridian' $\mathrm{F}$ bloom and 'Mauritius' $\mathrm{M}_{2}$ bloom. Thus, interplanting these two cultivars ensured the presence of pollen during the F blooms of both.

Pollination rate. In 1988 we sampled 2-day-old styles from 'Mauritius' and 'Floridian' inflorescences throughout their F bloom (at first only 'Mauritius', then 'Mauritius' and 'Floridian', and at the end only 'Floridian'). Pollination rate was determined in two orchards by two methods: a) by looking for pollen grains on the fresh stigma surface with a STM and b) by looking for germinating pollen grains in fixed, cleared and stained styles, with the help of a FLU.

No significant difference in pollination rate was found between the two methods used (Fig. 2), suggesting that germinating pollen grains were being observed in both. The very low pollination rate during the first part of the F bloom was unexpected. At that time 'Mauritius' and 'Floridian' M, pollen was available (Fig. 1), and bee activity was heavy. With the start of the $\mathrm{M}_{2}$ 'Mauritius' bloom, the pollination rate rose steeply, reaching $80 \%$. It remained at this high level during the 'Floridian' F bloom.

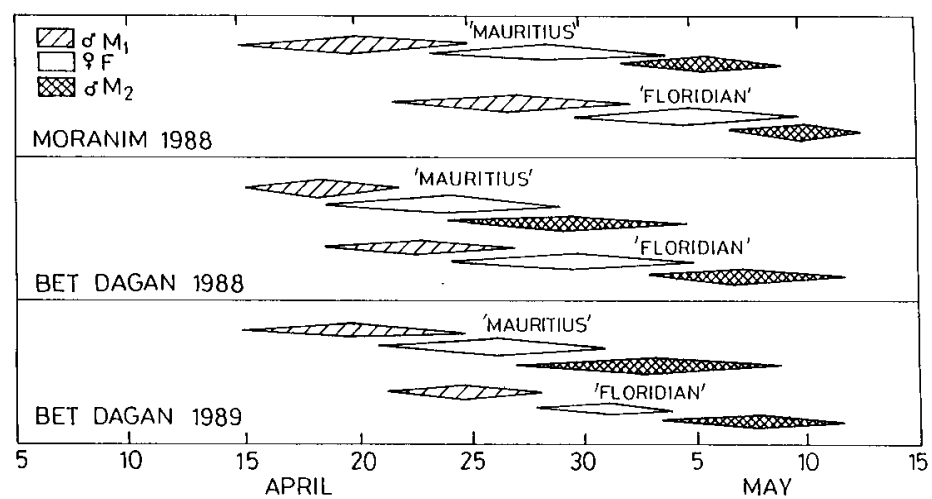

Fig. 1, Flowering phenology of 'Mauritius' and 'Floridian' in Moranim (1 988) and Bet Dagan (1988, 1989): male flowering $\left(\mathrm{M}_{1}\right)$, female flowering $(\mathrm{F})$, and pseudohermaphroditic flowering $\left(\mathrm{M}_{2}\right)$. The peak of flowering is represented by the center of the rhombus: its edges represent the start and termination of flowering.
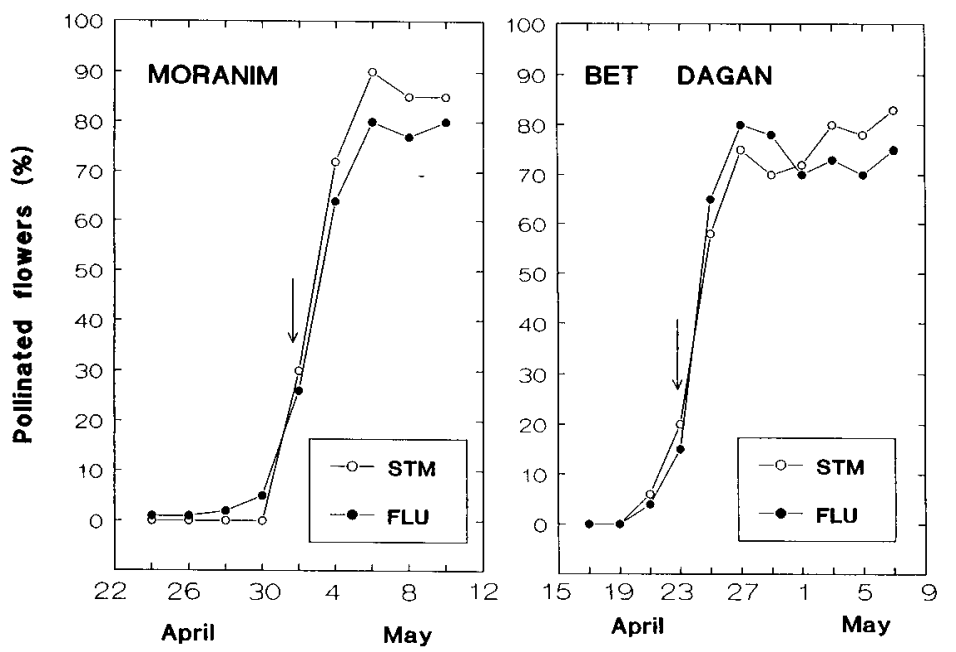

Fig. 2. Pollination rate in two lychee ('Mauritius' and 'Floridian') orchards, in 1988. Comparison between stereomicroscope (STM) and fluorescent microscope (FLU) methods. Arrows indicate the start of the 'Mauritius' $M_{2}$ bloom, Each value is the mean of 100 styles,

In 1989 we compared STM and SEM methods (Fig. 3). No significant difference in pollination rate was found between the two. The pollination rate was again negligible at the start of the $\mathrm{F}$ bloom.

Pollination rate was determined in additional lychee orchards (four in 1989 and 10 in 1990) covering all main lychee-growing areas in Israel, and the same pattern was found: at the start of the 'Mauritius' F bloom, pollination rates were low ( $0 \%$ to $20 \%)$; with the start of the $\mathrm{M}_{\mathrm{z}}$ bloom, rates increased to high values ( $80 \%$ to $90 \%$ ).

Number of pollen grains per flower. The pattern of changes in the number of pollen grains per pollinated style during the flowering period was similar to the pattern observed for pollination rate, starting with one or two pollen grains per stigma and rising to $>20$ with the start of the $\mathrm{M}_{2}$ bloom (Fig. 4). A very significant positive correlation $(r=0.93, P=0.001)$ was found between pollination rate and the number of pollen grains per flower.

Bee activity. Over a 2- year period ( 1989 and 1990), the number of bees present on the three types of 'Mauritius' inflorescences at their three stages of flowering was determined every other day, at around 0700,1000 , and $1700 \mathrm{HR}$ (Table 1). The following pattern was consistently found: the lowest number of bees was found at the $\mathrm{M}$, stage, it was much higher at the $\mathrm{M}_{2}$ stage, and was highest at the F stage. The mean number of bees per inflorescence found at the 


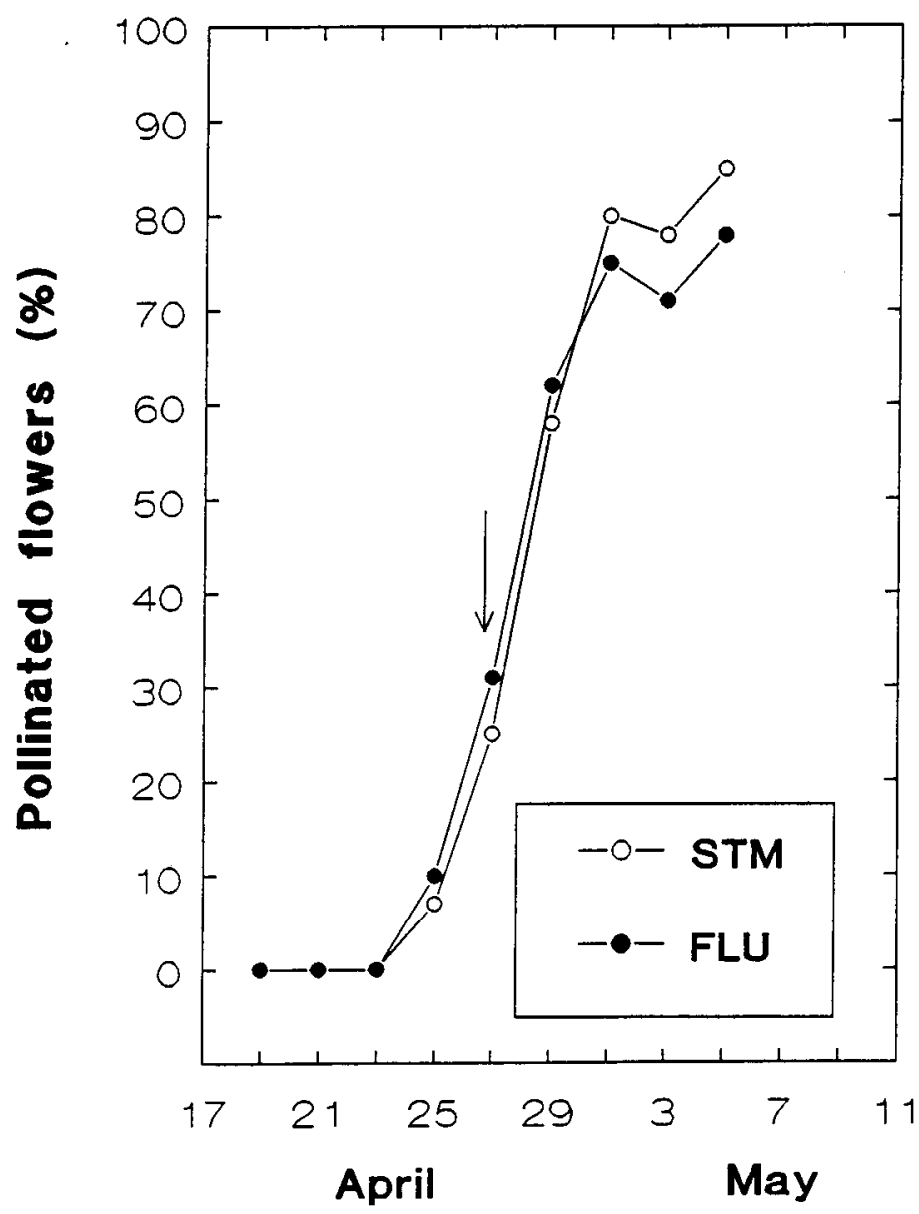

Fig. 3. Pollination rate in a lychee ('Mauritius' and 'Floridian') orchard in 1989 Comparison between stereomicroscope (STM) and scanning electron microscope (SEM) methods. Arrows indicate the start of the 'Mauritius' $\mathrm{M}_{2}$ bloom, Each value is the mean of 100 styles,

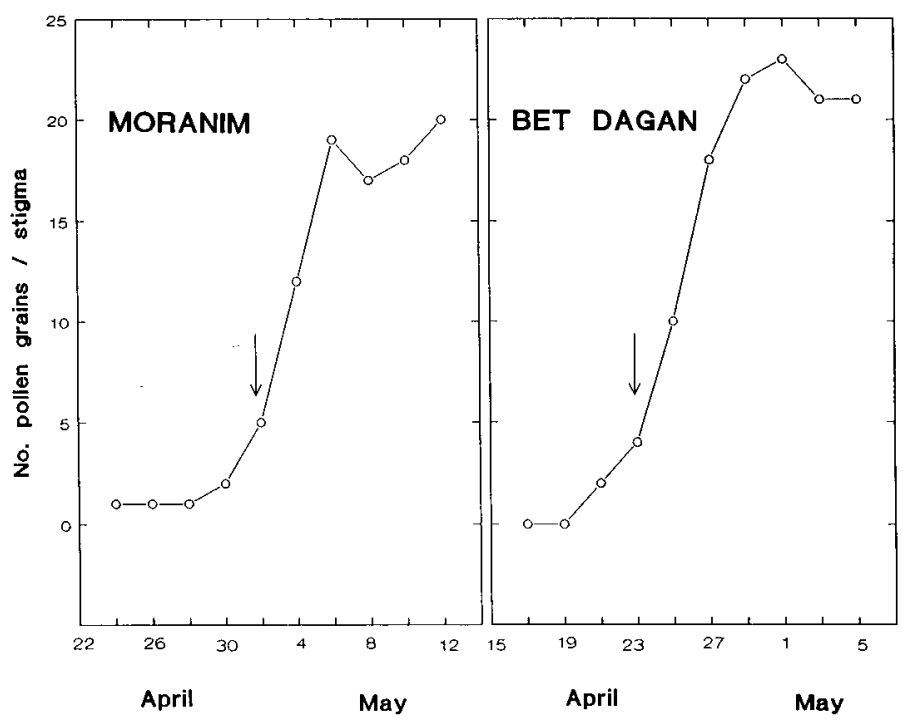

Fig. 4. Number of germinated pollen grains per pollinated flower in two lychee ('Mauritius' and 'Floridian') orchards in 1988. Arrows indicate the start of the 'Mauritius' $\mathrm{M}_{2}$ bloom.

$\mathrm{M}_{1}$ stage was 1.8 . It was 4.6 times higher at the $\mathrm{M}_{2}$ stage and 7.4 times higher at the $\mathrm{F}$ stage. The highest number of bees was consistent y found at $1000 \mathrm{HR}$.

Pollen on bee's body. Over a 2-year period (1989 and 1990), bees
Table 1. Mean number of bees counted on 'Mauritius' inflorescences at their three flowering stages during the flowering seasons of 1989 and 1990 (means of 10 inflorescences on five trees \pm SE).

\begin{tabular}{lccc}
\hline \hline Time (HR) & Male $_{1}$ & Male $_{2}$ & Female \\
\hline 0700 & $1.7 \pm 0.2$ & $7.4 \pm 0.4$ & $11.8 \pm 0.5$ \\
1000 & $2.1 \pm 0.2$ & $10.5 \pm 0.4$ & $17.2 \pm 0.7$ \\
1700 & $1.6 \pm 0.2$ & $6.9 \pm 0.4$ & $11.1 \pm 0.6$ \\
Mean & $1.8 \mathrm{c}^{7}$ & $8.3 \mathrm{~b}$ & $13.4 \mathrm{a}$ \\
\hline
\end{tabular}

${ }^{2}$ Results within a row followed by different letters differ significantly by Duncan's multiple range test, $\mathrm{P}=0.05$.

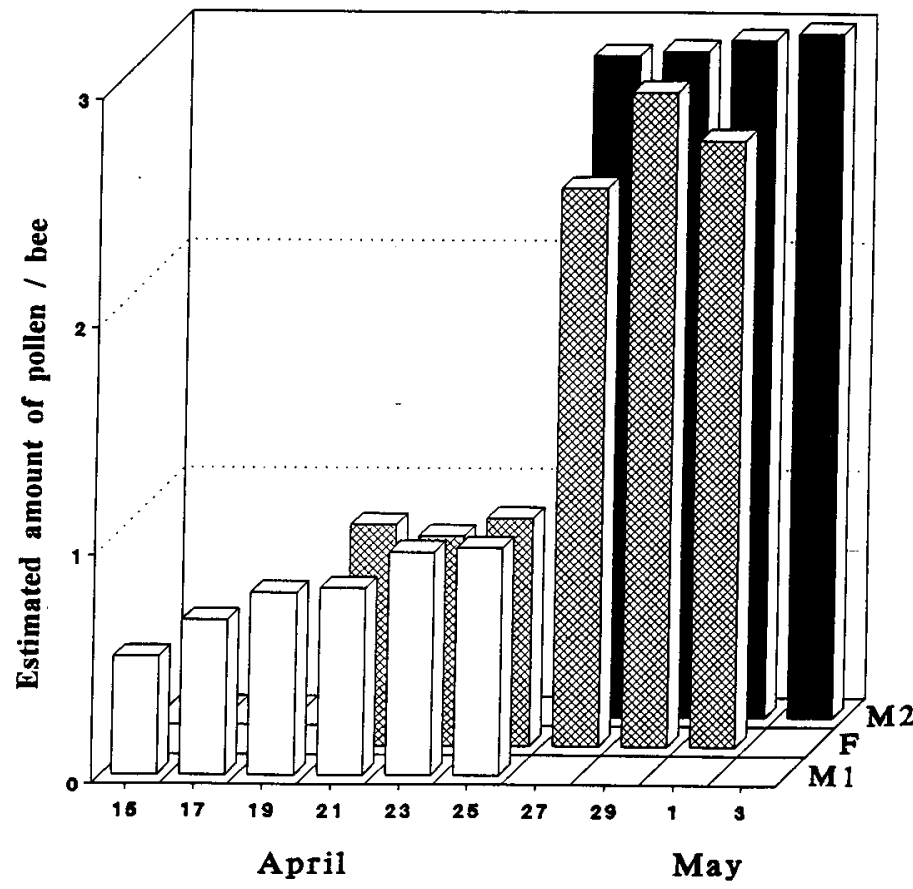

Fig. 5. Estimated amount of pollen found (by SEM observation) on bees caught on 'Mauritius' inflorescences at the three flowering stages $\left(\mathrm{M}_{1}, \mathrm{~F}\right.$, and $\left.\mathrm{M}_{2}\right)$. During the flowering seasons of 1989 and 1990, bees were collected every other day from inflorescences at the three flowering stages, at around 0700, 1000, and $1700 \mathrm{HR}$; 10 bees (two bees $\times$ five trees) were collected at each time point from each inflorescence type. Values are the daily means for 2 years. Results are given in terms of a logarithmic scale of 0 to $3: 0=$ no pollen; $1=$ up to 10 pollen grains; $2=$ tens of pollen grains; $3=$ hundreds of pollen grains .

visiting 'Mauritius' inflorescences at their three stages of flowering were caught every other day at around 700, 1000, and $1700 \mathrm{HR}$ and their bodies scanned in a SEM. The amount of pollen on the bees was estimated using a logarithmic scale (0 to 3 ). The similarity in flowering phenology during 1989 (Fig. 1) and 1990 enabled us to present mean daily values for these years (Fig. 5).

A strong similarity was found in the amount of pollen on bees visiting $\mathrm{F}$ and male $\left(\mathrm{M}_{1}\right.$ or $\mathrm{M}_{2}$ inflorescences on a particular day (Fig. 5), suggesting that the same bees tended to visit both male and F inflorescences. During the first $\mathrm{M}_{1}$ bloom, the mean estimate of pollen per bee was 0.85 (less than 10 pollen grains per bee). A dramatic increase occurred with the start of the second male $\left(\mathrm{M}_{2}\right)$ bloom: the estimated amount of pollen per bee increased to 2.8 (corresponding to hundreds of pollen grains per bee). This difference was found to be highly significant $(\mathrm{P}<0.001)$ by a contrast t-test, following the overall analysis of variance.

Nectar. In the 1989 and 1990 flowering seasons, nectar was collected from 'Mauritius' flowers, four times per year during peak flowering, at around 0600,0700,0800,0900, AND $1000 \mathrm{HR}$. At $0600 \mathrm{HR}$, no bee activity was observed; after $1000 \mathrm{HR}$, nectar 

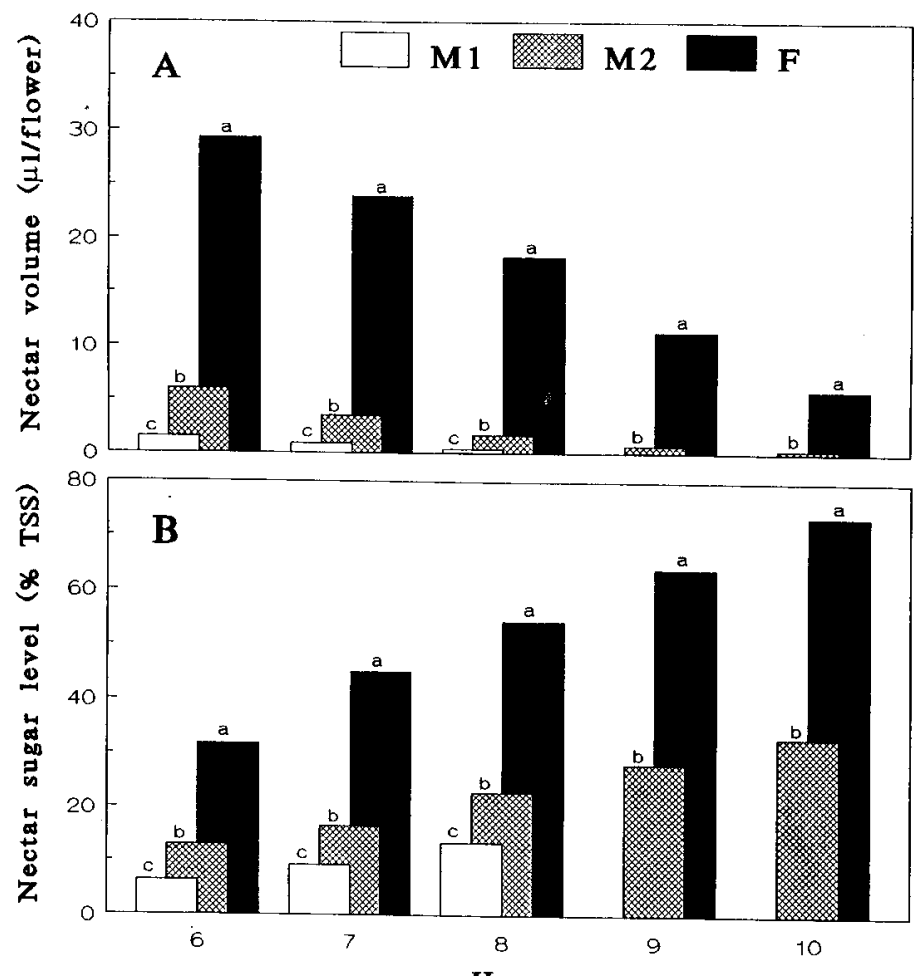

Fig. 6. Nectar volume $(\mu \mathrm{l})(\mathbf{A})$ and percentage of sugar (determined as TSS with a refractometer) (B) per 'Mauritius' lychee flower collected from the three flower types $\left(\mathrm{M}_{1}, \mathrm{M}_{2}\right.$ and $\left.\mathrm{F}\right)$ during the morning hours (at around 0600, 0700, 0800, 0900, and $1000 \mathrm{HR}$ ) Values are means of 1989 and 1990 seasons. Nectar was collected on four days each year, 10 flowers per time point for each flower type. Results relating to the same hour headed by different letters differ significantly by Duncan's multiple range test, $P=0.05$.

Table 2. Mean amount of nectar sugar (mg) per 'Mauritius' flower in each of the three flower types during the morning hours. Average for two seasons (1989 and 1990).

\begin{tabular}{lccc}
\hline Time & \multicolumn{3}{c}{ Flower type } \\
\cline { 2 - 4 }$(\mathrm{HR})$ & Male $_{1}$ & Male $_{2}$ & Female \\
\hline 0600 & $0.15 \mathrm{a}^{\mathrm{z}}$ & $0.82 \mathrm{a}$ & $\mathbf{1 0 . 5 \mathrm { ab }}$ \\
0700 & $0.10 \mathrm{~b}$ & $0.72 \mathrm{ab}$ & $12.8 \mathrm{a}$ \\
0800 & $0.07 \mathrm{c}$ & $0.50 \mathrm{~b}$ & $12.2 \mathrm{a}$ \\
0900 & $\ldots .-{ }^{y}$ & $0.27 \mathrm{c}$ & $10.3 \mathrm{ab}$ \\
1000 & --- & $0.18 \mathrm{c}$ & $7.1 \mathrm{~b}$ \\
Mean & $0.10 \mathrm{C}$ & $0.50 \mathrm{~B}$ & $10.6 \mathrm{~A}$ \\
\hline
\end{tabular}

${ }^{2}$ Results within columns with different lowercase letters and results within a row followed by different uppercase letters differ significantly by Duncan's multiple range test, $P=0.05$.

${ }^{y}$ No nectar could be collected.

volumes were negligible. There were no significant differences in the values of the parameters determined on these 8 days. Thus, the results are presented as means of all determinations at a particular hour (Fig. 6, Table 2).

Nectar volume per flower decreased significantly between 0600 and $1000 \mathrm{HR}$ in all three flower types: in F flowers from $29 \mu \mathrm{l}$ to $6 \mu \mathrm{l}$, in $\mathrm{M}_{2}$ flowers from 6 to $0.3 \mu \mathrm{l}$, and in $\mathrm{M}_{1}$ flowers from 1.5 to $0 \mu \mathrm{l}$ (Fig. 6A). The differences between the three flower types were significant at all sampling times.

The percentage of sugar in the nectar (determined as TSS by refractometer) increased significantly from $0600 \mathrm{HR}$ onwards, in all three flower types (Fig. 6B). In F flowers from 32\% to $74 \%$ (at 1000 $\mathrm{HR}$ ), in $\mathrm{M}_{2}$ flowers from $13 \%$ to $33 \%$ (at $1000 \mathrm{HR}$ ), and in Ml flowers
Table 3. The percentages of glucose, fructose, and sucrose in the total nectar sugar, from the three types of 'Mauritius' lychee flowers during the morning hours. Average of one season (1989), four sampling dates $(21,23,25$, and 27 Apr.), and five replicates per hour (at around 0600,0700,0800,0900, and $1000 \mathrm{HR}$ ).

\begin{tabular}{lccc}
\hline \hline $\begin{array}{l}\text { Flower } \\
\text { type }\end{array}$ & $\begin{array}{c}\text { Glucose } \\
\%\end{array}$ & $\begin{array}{c}\text { Fructose } \\
\%\end{array}$ & $\begin{array}{c}\text { Sucrose } \\
\%\end{array}$ \\
\hline Male $_{1}$ & $42.2 \pm 0.8$ & $39.3+0.9$ & $18.5 \pm 1.0$ \\
Male $_{2}$ & $43.1 \pm 0.7$ & $38.3 \pm 0.8$ & $18.6 \pm 1.0$ \\
Female $_{\text {Mean }}^{42.8 \pm 0.8}$ & $39.9 \pm 0.8$ & $17.3 \pm 0.8$ \\
& $42.7 \mathrm{a}^{2}$ & $39.2 \mathrm{~b}$ & $18.1 \mathrm{c}$
\end{tabular}

${ }^{\overline{2}}$ Data were analyzed by analysis of variance, using the repeated measures structure of the experiment. Results within a row followed by different letters differ significantly by Duncan's multiple range test, $\mathrm{P}=0.05$.

from $6.3 \%$ to $13 \%$ (at $0800 \mathrm{~m}$ ). No nectar could be extracted from M, flowers at 0900 or $1000 \mathrm{HR}$. The differences between the three flower types were significant at all sampling times. The volume of nectar was multiplied by the percentage of sugar to obtain the amount of sugar per flower (Corbet, 1979) (Table 2). The mean amount of sugar per $\mathrm{F}$ flower was 20 times more than that per $\mathrm{M}_{2}$ flower, and 100 times more than that per $\mathrm{Ml}$ flower.

Ratio of sugars in the nectar. In 1989, a large volume of nectar $(1000 \mu \mathrm{l})$ was collected at each sampling from each flower type. Three sugars were identified by HPLC: glucose, fructose, and sucrose. No significant differences in the ratio of the three sugars was found at any of the sampling times. Table 3 presents the mean percentage of the three sugars in the nectar of the three flower types.

No significant differences in the percentages of glucose, fructose or sucrose were found in nectar from any of the three flower types (Table 3). The mean percentages were: glucose 43, fructose 39 and sucrose 18 . The differences between percentages were found to be significant $(\mathrm{P}=0.05)$.

\section{Discussion}

Lychee has three types of functionally unisex flowers (Costes, 1988; Joubert, 1986), and a temporal overlapping of the F bloom and pollen-releasing blooms $\left(\mathrm{M}_{1}\right.$ and $\left.\mathrm{M}_{2}\right)$ is required for pollination. In this study (Fig. 1) and others (Deganiet al., 1995a; Stern et al., 1993 b), we found this overlap to be only partial within the same cultivar ('Mauritius' or 'Floridian'). However, full overlapping usually occurs when these two cultivars are planted together. Thus, as far as pollination rate is concerned, there seems to be an inherent advantage to planting two or more cultivars together, thereby ensuring the presence of pollen during the F loom. Such mixed plots may also be beneficial in improving the yield of cultivars that benefit from crosspollination (Degani et al., 1995a; Stem et al., 1993b).

During this study we found that the bee was either the only pollinator visiting lychee blooms or the dominant one. In other countries, a large assortment of pollinating agents has been found (Butcher, 1956, 1957; DeGrandi-Hoffman, 1987; Khan, 1929; King et al., 1989; Pandey and Yadava, 1970), and the bee is not the dominant species. The predominance of bees in this study apparently reflects the insect fauna in and around Israeli lychee orchards.

This is the first report to describe the nectar in lychee flowers. Vast differences in nectar volume and sugar percentage in the nectar were found among the three flower types in 'Mauritius': the lowest values were found in $\mathbf{M}_{1}$ flowers, medium values in $\mathbf{M}_{2}$ flowers and exceedingly high values in F flowers (Fig. 6, Table 2). Nectary sizes in the three flower types reflect nectar production: 


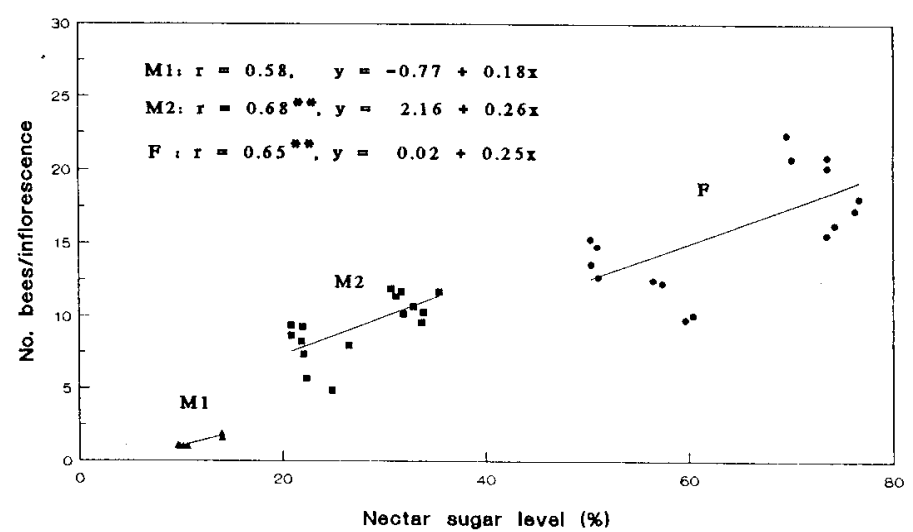

Fig. 7. The correlation between sugar concentration in nectar collected from the three flower types $\left(\mathrm{F}, \mathrm{M}_{1}, \mathrm{M}_{2}\right)$ andlhe number of bees counted on the corresponding inflorescences. Figures are means of 1989 and 1990 data (data for each parameter are presented in Fig. 6 and Table 1). **significant at $P=0.01$.

they are very small in $M_{1}$ flowers, of medium size in $M_{2}$ flowers and extremely large in F flowers (Scholefield, 1982). Each 'Mauritius' inflorescence contains over $100 \mathrm{~F}$ flowers that are all open at the same time. The tree is densely covered with such inflorescences. Thus, the 'Mauritius' lychee F bloom can be considered a very rich source of nectar, both in quantity and quality.

We calculated the correlation between bee density on 'Mauritius' inflorescences at the three flowering stages (Table 1 ) and the nectar volume per flower (Fig. 6A), the percentage of sugars in the nectar (Fig. 6B), and the amount of sugar per flower (Table 2). For $\mathrm{M}_{2}$ and $\mathrm{F}$ blooms, we found a significant positive correlation between bee density and the percentage of sugars in the nectar (Fig. 7), and significant negative correlations between bee density and nectar volume per flower $\left(\mathrm{M}_{2}: r=-0.50, P=0.05 ; \mathrm{F}: r=-0.67, P=0.01\right)$ and the amount of sugar per flower $\left(\mathrm{M}_{2}: r=-0.55, P=0.05 ; \mathrm{F}: r\right.$ $=-0.70, P=0.05)$. These results indicate that in 'Mauritius' lychee, the dominant attractant for bees is the percentage of sugar in the nectar. When a bee can easily fill its honey stomach with nectar from a few flowers on one inflorescence (Free, 1993), the higher its sugar concentration, the higher the net energy yield will be per flight (Heinrich, 1983; Seeley, 1985; von Frisch, 1967).

The special attractiveness of the F bloom is not accidental: it reflects the fact that fruit can set at that time only. The abundance of bees in the orchard during the F bloom may have a positive effect on bee visitation to $M_{1}$ and $M_{2}$ blooms. The $M_{2}$ bloom was found to be much more attractive to-bees than the $M_{1}$ bloom (Table 1), apparently because it is a much richer source of nectar and sugars (Fig. 6, Table 2). The $\mathrm{M}_{1}$ bloom was also found to play a minor role in pollination (Figs. 2, 3, and 5).

The inferiority of the $M_{1}$ bloom is surprising and difficult to explain. If this phenomenon is found to be a universal feature in lychee, it may indicate that its native pollinator has been more appreciative of the $\mathbf{M}_{1}$ bloom than the honeybee.

No significant differences in the concentrations of glucose, fructose, and sucrose in the nectar were found between the three lychee flower types (Table 3). This uniformity is typical for different flower types in the same plant species (Barker and Lehner, 1974; Percival, 196 1). The combined level of the monosaccharides glucose and fructose in the nectar was more than $80 \%$, while sucrose level was less than $20 \%$ (Table 3). The fact that the lychee bloom is so attractive to bees may support Baker and Baker's (1983) conclusion that bees prefer nectar which is low in sucrose.

The amount of pollen found on bees sampled from $\mathrm{F}$ and $\mathrm{M}$, inflorescences was higher by two orders of magnitude than that found on bees sampled during the $\mathrm{M}_{1}$ bloom (Fig. 5). This large difference appears to result from the pronounced differences in the nectar found between $\mathrm{M}_{1}$ and $\mathrm{M}_{2}$ flowers (Fig. 6, Table 2). We can assume that bees visiting an inflorescence during its $\mathrm{M}_{1}$ bloom will be disappointed with the meager yield and abandon it immediately, whereas bees visiting an inflorescence during its $\mathrm{M}_{2}$ bloom will visit a large number of flowers and get covered with plenty of pollen.

\section{Literature Cited}

Anderson, D. L., M. Sedgley, J.R.T. Short, and A.J. Allwood. 1982. Insect pollination of mango in north Australia. Austral. J. Agr. Res. 33:541548

Baker, H.G. and 1. Baker. 1983. Floral nectar sugar constituents in relation to pollination type, p. 117-141. In: C.E. Jones and K.J, Little (eds.). Handbook of experimental pollination biology. Van Nostrand Reinhold Co., New York.

Barker, R.J. and Y. Lehner. 1974. Acceptance and sustenance value of naturally occurring sugars fed to newly emerged adult workers of honeybees (Apis mellifera L.). J. Expt. Zool. 187:277-286.

Butcher, F.G. 1956. Bees pollinate lychee blooms. Proc. Fla. Lychee Growers Assn. 3:59-60.

Butcher, F.G. 1957. Pollinating insects on lychee blossoms. Proc. Fla. Stat. Hort. Soc. 70:326-328;

Chaturvedi, R.B. and G.K. Saxena. 1965. Studies on the blossom biology of litchi (Litchi chinensis Sonn.). Allahabad Farmer 39: 10- 13.

Corbet, S.A. 1979. Humidity, nectar, and insects visiting flowers, with special reference to Crataegus, Tilia and Echium. Ecol. Entomol. 4:922.

Costes, E. 1988. Analyze architecturate et modelisation du litchi (Litchi chinensis Sonn.). PhD diss., Univ. of Montpelier, France.

Cruden, R. W., S.M. Herman, and M. Peterson. 1983. Patterns of nectar production and plant pollination convolution, p. 80-125. In: B. Benley and T. Elias (eds.). The biology of nectaries. Columbia Univ. Press, New York.

Degani, C., A. Beiles, R. El-Batsri, M. Goren, and S. Gazit. 1995a. Identifying lychee cultivars by isozyme analysis. J. Amer. Soc. Hort. Sci. 120:307-312.

Degani, C., R.A. Stern, R. El-Batsri, and S. Gazit. 1995b.

DeGrandi-Hoffman, G. 1987. The honeybee pollination component of horticultural crop production systems. Hort. Rev. 9:237-260.

Eisikowitch, D. and H. Melamud. 1982. A preliminary report on the role of honeybees in avocado pollination. (In Hebrew.) Alon Hanotea 37:1929.

Fivaz, J. 1994. Litichi production in Israel, S. Afr. Litichi Growers' Assn. Yrbk. 6:39-41.

Free, J.B. 1993. Insect pollination of crops, 2nd ed. Academic Press, London.

Groff, G.W. 1943. Some ecological factors involved in successful lychee culture. Proc. Fla. State Hort. Soc. 56: 134-155.

Heinrich, B. 1983. Insect foraging energetic, p. 187-214. In: E.C. Jones and R.T. Little (eds.). Handbook of experimental pollination biology. Van Nostrand Reinhold Co., New York.

Ish-Am, G. and D. Eisikowitch. 1993. The behaviour of honey bees (Apis mellifera) visiting avocado (Persea americana) flowers and their contribution to its pollination. J. Apicult. Res. 32: 175-1 86.

Jennersten, O., L. Berg, and C. Lehman. 1988. Phonological differences in pollinator visitation, pollen deposition, and seed set in the sticky catchfly, Viscaria vdgaris. J. Ecol. 76:1111-1132.

Joubert, A.J. 1986. Litchi, p. 233-246. In: S.P, Monselise (cd.). Handbook of fruit set and development. CRC Press, Boca Raton, Fla.

Kearns, C.A. and D. W. Inouye. 1993. Techniques for pollination biologists. Univ. press of Colorado.

Khan, K.S. 1929. Pollination and fruit formation in litchi. Agr. J. India 24:183-187.

King, J., E.M. Exley, and V. Vithange. 1989. Insect pollination for yield increases in lychee, p. 142-145. In: D.J. Batten (ed.). Proc. 4th Austral. conf. tree nut crops. Exotic Fruit Growers Assn., Lismore, Austral. 
Martin, F.V. 1959. Staining and observing pollen tubes in style by means of fluorescence. Staining Technol. 34: 125-1 28.

McConchie, C.A. and D.J. Batten. 1989. Floral biology and fruit set in lychee. Proc. 2nd Natl. Lychee Seminar, Cairns, Austral. p. 71-74.

McGregor, S.E. 1976. Insect pollination of cultivated crop plants. U.S Dept. Agr.-Agr. Res. Ser. no. 496:247-248.

Menzel, CM. 1984. The pattern and control of reproductive development in lychee: a review. Scientia Hort. 22:333-341.

Pandey, R.S. and R.P.S. Yadava. 1970. Pollination of litchi (Litchi chinensis) by insects with special reference to honeybees. J. Apicult. Res. 9:103-105.

Percival, M. 1961. Types of reference nectar in angiosperms. New Phytol. 60:235-281.

Piccaglia, R. and G.C. Galletti. 1988. Sugar and sugar alcohol determination in feedstuffs by HRGC, HPLC and enzymatic analysis. J. Sci. Food Agr. 45:203-213.

Pivovaro, S.Z. 1974. Studies on the floral biology and the influence of growth regulators on fruit set, size and drop of Litchi chinensis Sonn.
(Hebrew with English summary). MS thesis. Faculty of Agr., The Hebrew Univ. of Jerusalem, Israel.

Rabat, M. 1970. Flowering, pollination and fruit-set in mango flowers, cv. Haden (Hebrew). MS thesis. Faculty of Agr., The Hebrew Univ. of' Jerusalem, Israel.

Scholefield, P.B. 1982. A scanning electron microscope study of flowers of avocado, litchi, macadamia, and mango. Scientia Hort. 16:263-272. Seeley, T.D. 1985. Food collection, p. 80-103. In: T.D. Seeley (ed.). Honeybee ecology. Princeton Univ. Press, Princeton, N.J.

Stern, R. A., 1. Adato, M. Goren, D. Eisenstein, and S. Gazit. 1993a. Effect of autumnal water stress on litchi flowering and yield in Israel. Scientia Hort. 54:295-302.

Stem, R. A., S. Gazit, R. El-Batsri, and C. Degani. 1993 b. Pollen parent effect on outcrossing rate, yield and fruit characteristics of 'Floridian' and 'Mauritius' lychee. J. Amer. Soc. Hort. Sci. 118: 109-1 14.

von Frisch, K. 1967. Dependence of dance on the profitability of foraging activity, p. 236-256. In: K. von Frisch (ed.). The dance language and orientation of bees. Harvard Univ. Press, Cambridge, Mass. 